\title{
UNDERSTANDING COMMUNITY BEHAVIORS IN FOR- PROFIT OPEN SOURCE HARDWARE PROJECTS
}

\author{
Li, Zhuoxuan (1); Seering, Warren (1); Tao, Tiffany (1); Cao, Shengnan (2) \\ 1: Massachusetts Institute of Technology; 2: Northeastern University
}

\begin{abstract}
Free contributors have successfully shown the potential in large/complex software co-creation in the Free and Open Source Software Movement, triggering many discussions and exploration ventures from academia to industry and to the government. Though many research efforts explored whether the same level of co-creation efforts could take place broadly in the hardware realm, very few research studies focus on profit-seeking hardware projects initiated by companies. In fact, the specific nature of being tangible and profitable makes company-led open source hardware projects suspicious to be really "open" to contributors. Community has been identified as the critical driver in many open projects. By reviewing the evolution of company-community interactions over time and different community behaviors in different open development context, authors in this paper hope to identify best communitycompany interaction forms for open source hardware companies. Using grounded theory and case studies, we construct a framework to describe and identify company community's different behaviors and different roles.
\end{abstract}

Keywords: Open source design, Open innovation, Design management, Collaborative design

\section{Contact:}

Li, Zhuoxuan

Massachusetts Institute of Technology

Mechanical Engineering

United States of America

zxli@mit.edu

Cite this article: Li, Z., Seering, W., Tao, T., Cao, S. (2019) 'Understanding Community Behaviors in For-Profit Open Source Hardware Projects', in Proceedings of the 22nd International Conference on Engineering Design (ICED19), Delft, The Netherlands, 5-8 August 2019. DOI:10.1017/dsi.2019.246 


\section{INTRODUCTION}

Free contributors have shown their willingness to participate in distributed, collaborative production of large/complex software projects (von Hippel 2001; Way 2002; Weber 2004; Bagozzi \& Dholakia 2006). More recently, researchers have started to explore the viability of open source as a design model in the hardware realm, formulating the research field of open design, open source design, open source hardware and open source product development (Rubow 2008; Mellis \& Buechley 2012; Kyriakou \& Nickerson 2014; Moritz et al., 2016). In recent years, emergence of cheaper hardware development tools and maker spaces allow people to participate in global open source hardware projects in a distributed manner (Malinen et al., 2011; Hellenes 2016; Moritz et al., 2016). As opposed to an in-house product design process, in open design, volunteers discuss the product design with the project's leader(s) and each other in local get-togethers or virtual online forums. In their own garages or local maker spaces, they refine, modify and customize the shared open source files, and then shares the new design back to the community. People are self-motivated to build on each other's progress locally or remotely, using their own resources to advance the projects. A good example is RepRap - a self-replicable 3D printer project, initiated by a UK professor, but created by global volunteers, lowering the price of a 3D printer from over 10,000 euros to 500 euros in 2 years (Bruijn 2010). It shed hope that open source could one day take place in larger and more complex hardware projects. Though the RepRap project was initiated for a non-profit-seeking purpose, it showed the volunteers' power of creating a disruptive innovation and starting a new consumer market. The RepRap project also gave birth to the biggest global 3D printing community, and its first spin-off startup - Makerbot. Unlike open source software communities, who normally have contradictory interests over the interests of open source spinoffs (Dahlander \& Magnusson 2008), RepRap communities didn't seem bothered much by this profit-seeking action. In fact, MakerBot became a superhero in the global 3D printing community as it provided an easier to use and better quality 3D printer for the community with a reasonable price. It kept all design files of all products open source and built an online 3D file sharing platform (http://www.thingiverse.com/) to help its community in diffusing their 3D printed inventions quickly. However, in 2012, MakerBot announced their go-close decision after 4 years' rapid growth as a pure open source company. This decision greatly angered the global 3D printing community. Voices like "Makerbot betrayed open spirit!" were all over the Internet (CNET 2012). This event alerted other profit-seekers to reconsider the sustainability of building an opens source company and the role of community ( $\mathrm{Li}$ et al., 2017) - if a project were initiated, in the very beginning, for a profit-seeking purpose, would people still contribute knowing someone else would finally take advantage of their contributions? If so, would the community's behaviors be different from the ones in non-profit-seeking projects?

In order to answer these questions, the paper is organized as follows: In Section 2, we summarize the relevant literature: 1) the concepts of customers and community; 2) evolution of customer-company interactions; 3) community contribution in non-profit-seeking context. In Section 3, we explain our research methods and motivations. In Section 4, we propose two qualitative frameworks of the community's roles and behaviors. Then, using interview data, we summarize what factors will influence the community's contribution in profit-seeking open source projects.

\section{DEFINITIONS AND LITERATURE REVIEW}

\subsection{The concepts of customer and community}

In marketing research of consumer behaviors, the concept of brand community was first proposed and defined as a group of people who share admiration of a brand (Muniz \& Thomas 2001). Research showed that the community being loyal to the brand was a great resource for firms in acquiring new product ideas, collecting user experience feedback and using their power of word of mouth which is higher than that of ordinary customers (Muniz \& Thomas 2001; Habibi et al., 2014). Since then, brand community has been regarded as an important resource for companies' marketing power. With the takeoff of Internet technology, communication between customers and companies and among customers became ubiquitous, instant and almost free of charge. Many firms built their online forums so that customers could be able to actively interact with companies to express their needs and experience and give advice or suggestions. Actually, not only customers but anyone who is interested 
in the firm, firm brand, or firm products is able to express himself on the firm's virtual forum and be heard by the internal team and other forum members. As a result, the difference between a firm's customers and community is unclear. In this paper, we define community as people who have purchased the firm's products or people who actively participate in the firm's online or offline activities.

\subsection{Evolution of customer - company interaction in profit-seeking context}

Before the Internet age, around 1995, it was very costly for firms to directly interact with their customers in a large-scale way, especially for business-to-consumer model firms. Customers could only passively receive product information from companies, such as through TV, newspaper ads, fliers, posters or the yellow pages. Brandfest, a party-like get-together organized by the firm for people who admire a brand, was effective in building up a brand community, collecting product ideas and feedback, and turning passive customers into loyal ones (Muniz \& Thomas 2001). In 2004, value cocreation between customers and firms was first proposed and advocated as an effective way to increase the firm's value creation (Prahalad \& Ramaswamy 2004). In it, the Internet was suggested for use as a value co-creation platform. Since then, the company-customer relationship shifted from company-led to customer-centered, resulting in the emergence of new interaction forms, such as ideas crowdsourcing (Martinez \& Walton 2013), problem solving competitions (Alexy \& Reitzig 2013; Lakhani 2016), and the "Free and Open Source Software Movement" (Lakhani \& Wolf 2005; Benkler 2002; Dahlander 2007; von Hipel 2002).

\subsection{Community contribution in non profit-seeking contexts}

Previous studies about community contributions in non-profit-seeking contexts fall into four major areas - 1) open source software, 2) user innovation, 3) closed source company open innovation, 4) open source product development. In the open source software context, the community acts as the developers and users of the software. Gacek et al proposed a taxonomy of community roles based on their technological contribution (Gacek \& Arief 2004). The four different roles include passive users, non-developers, co-developers, and core-developers. Passive users only download and use software, and seek help in the community when they encounter issues. Non-developers do similar things, but also contribute to the project by reporting bugs, editing documentation, suggesting new features and pursuing other non-development-related actions. Co-developers contribute to low-level development, such as fixing bugs and reviewing code. Core-developers contribute to core development, as well as project maintenance and new version updates.

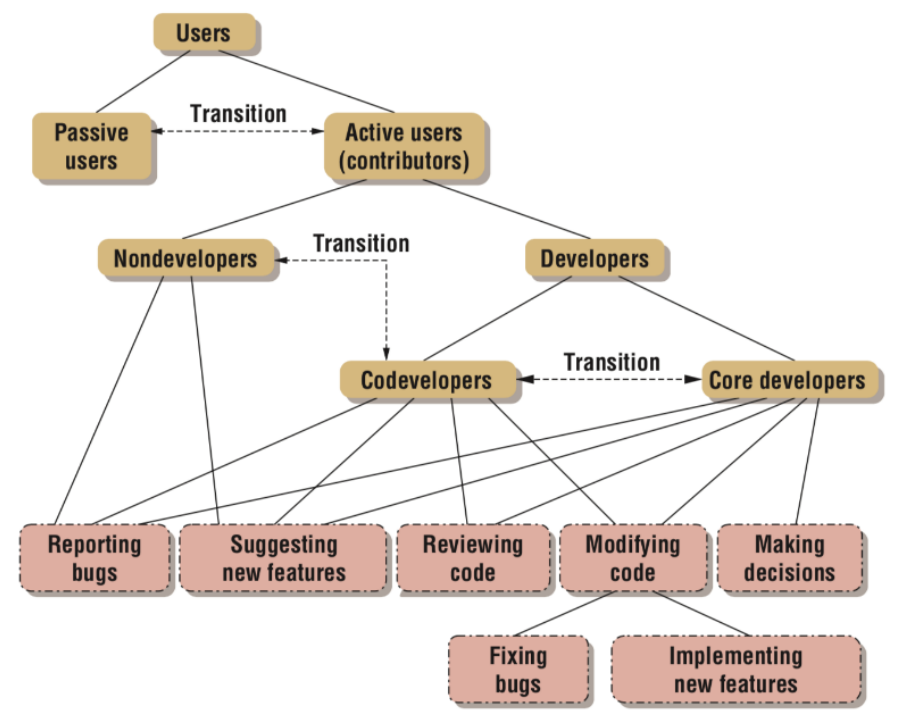

Figure 1. Taxonomy of open source software community (Gacek \& Arief 2004)

Von Hippel et al observed that people might innovate for their own utilitarian purposes (von Hippel 2017). The innovator is therefore called a user innovator and the innovation is called user innovation. A user innovation may be developed by only the inventor or with the community - a group of people who share an interest in the project. Four types of contributors in a user innovation project were identified. 
They are users, participators, helpers and producers (von Hippel 2017). Users contribute for the purpose of personal usage. Their behaviors include purchasing materials to replicate and customize existing solutions or to build and test their own solutions, and sharing their achievements with the community. They also seek help from the community forum when encountering problems during development. Participators contribute for learning purposes. They may or may not replicate the solution, but they follow the project progress to learn. Helpers contribute due to their social responsibilities, altruism or reciprocity. They don't necessarily build physical products, but they offer help when people need it. Producers contribute because they want to capture value from the project when the solution is mature. They follow the project's progress and associated new inventions closely. Producers offer help to the community builders in completing their inventions so that they can save R\&D cost. They also test the invention on their products to see if they can gain technology competitiveness.

Open Innovation is a concept invented by Chesbrough in 2003, advocating that knowledge flowing across organizational boundaries would create more value for companies (Gassmann et al., 2010). The community in the open innovation contexts acts as an external knowledge resource for firms. Activities, like idea crowdsourcing, were initiated by big companies such as Dell and P\&G (Harhoff \& Lakhani 2016). Most participants were brand community members who were willing to share their opinions, ideas or solutions on the company's open innovation platform to help address the company's internal challenges. Later, open innovation expanded to the problem-solving competition field (Lakhani 2016). Two roles emerged in competitions, Solvers and Interested Observers. Solvers aimed to provide solutions to the challenges, motivated by intrinsic motivations such as fun of solving or extrinsic motivations such as financial reward or job opportunities with the competition sponsors. Interested Observers helped to clarify problem formulations and to promote the competition in their social networks (Lakhani 2016).

In non-profit-seeking open source hardware contexts, the community act as Developers and Interested Observers. They demonstrate collaborative, globally distributed and locally centralized characteristics (Moritz et al., 2016). The community behaviors are very similar to the ones of user innovation communities, but open source hardware project initiators are more likely to apply for open source licenses. For example, a project initiator would choose a restricted open source license, such as GPL, for the project to prohibit project commercialization by other producers. Bonvoisin further proposed the concept of open source product development defined as "the development of open source hardware products in a collaborative process permitting the participation of any person interested." He argued that depending on the openness of both product and process, the community would have different freedom of participation, therefore resulting in different behaviors (Bonvoisin et al., 2017).

\subsection{Definition of an open source hardware firm}

The definition of open source hardware, according to the Open Source Hardware Association (https://www.oshwa.org/) is "Open source hardware is hardware whose design is made publicly available so that anyone can study, modify, distribute, make, and sell the design or hardware based on that design." To be considered as an open source hardware firm in this paper, firms are required to satisfy three criteria. First, firms must have at least one open source hardware product with product blueprints, CAD files, software code, and assembly instructions available online and licensed under an open source license within two years of the firm's incorporation. The open-sourced design files need to demonstrate transparency, accessibility and affordability (Fjeldsted et al., 2012). Second, firms must demonstrate an active relationship (on average more than 1 post/per month on a forum) with their community. Third, firms must have already generated or have actively attempted to generate revenue via the open source products.

\section{RESEARCH METHODS}

\subsection{Building the framework using grounded theory}

The phenomena of entrepreneurs running an open source hardware firm first emerged in around 2008. So far, the total volume of global open source hardware firms is still very small, making data collection difficult. Therefore, we choose grounded theory as our major research method (Charmaz 2014). Unlike inductive research methods, grounded theory is very suitable for uncovering hidden theories or building new theories from novel social phenomenon. According to grounded theory, 
researchers immerse themselves immediately into social activities without preselecting any existing theories. Using field observations, interviews, or surveys to collect qualitative data, researchers can use coding, tagging and grouping skills to ground a theory explaining the research questions. Then researchers need to compare the grounded theory to existing theory in order to determine whether the grounded theory is newly discovered or is just an alternative statement of an existing theory or theories (Charmaz 2014).

Over four years of research, we have obtained a list of 127 open source hardware companies worldwide from the Open Source Hardware Association, Wevolver, and Google search. By June of 2017, we completed interviews via Skype video or in person with 37 founders from 37 firms. The interviews started in June of 2015 and are continuing. The 37 firms are from 13 countries and have ages from 1 to 15 years. There are 2 females and 35 males in the cohort. In addition, we have interviewed 13 community members that were selected from M5Stack (an IoT device), OpenROV (an underwater drone), Ultimaker (a 3D printer), Plen (a Humanoid Robot) and Arduino (a Microprocessor) as these firms represent 5 different countries and 5 different product fields. The community interviewees behaved actively on the firms' forums within two years after forum's began. A case study approach was chosen because we wish to triangulate what we learned from interview data. We scraped and analyzed the forum data from OpenROV (https://www.openrov.com/) and Ultimaker (https://ultimaker.com/) to develop our frameworks. In order to avoid subjectivity bias, we had 4 scholars independently assign 150 threads randomly from each forum to a separate framework. Another 2 scholars each independently coded the 37 entrepreneurs' interview scripts from our previous work, in which they described their community behaviors, to establish two more frameworks. Then we compared and merged the six frameworks into a more robust one that is shown in Figure 2 and described further in Table 1. Finally, we compared this proposed framework with the open source software community taxonomy and user innovation project community taxonomy. From this work we determined that we hadn't recreated one of the existing theories from another research field.

\subsection{Case choice and introduction}

OpenROV (https://www.openrov.com/) is a startup company that specializes in the design and manufacture of ROVs for exploration purposes. Established in 2011, it was founded by David Lang and Eric Stakepoles in Berkeley, California, and initially started by selling a Do It Yourself (DIY) kit, OpenROV. OpenROV's design files are open sourced, allowing anyone to build and hack its designs for free. Due to OpenROV's open development model, it develops and moderates a forum site where people can share questions and concerns. Its forum is well-documented and dates as far back as when the company first started, which makes it a good case study to draw data points from. Underwater robotics is a technology with a fast-growing market, which gave us the opportunity to look at a company whose market is rapidly growing.

Another case we draw on is from the 3D printing industry. Ultimaker (https://ultimaker.com/) is one of the biggest players in consumer 3D printing. In 2011, Ultimaker was founded in Geldermalsen, Netherland and is driven to empower people with technology and innovation through 3D printing. Four different 3D printers are currently for sale. The first product launched was a DIY 3D printer, Ultimaker Original. For this printer, all the designs are also open sourced, similar to OpenROV's first product. Ultimaker also provides a well-documented forum site dated to 2011, which makes it a good candidate for a case study. OpenROV and Ultimaker have similar length of history. Both started by selling open source products, then moved to proprietary mode.

\section{FINDINGS}

\subsection{Community behaviors}

In order to understand community behaviors in a firm-led open source hardware project, we need to understand the uniqueness of open source product development. In comparison to the four contexts in Section 2.3, firm-led open source hardware projects have the following characteristics. 1) The project is initiated for a profit-seeking purpose. As a consequence, the development process has critical "deadlines" and the internal team will lead in making development decisions. 2) Because the project is open source, the community may have already formed before the products are available in the market. 3) The assembly process for DIY (Do-It-Yourself) projects actually provides a learning opportunity for 
customers to understand the design of the product, making it easier for them to discover issues or bugs. Moreover, hands-on experience helps deepening connections between customers and products. 4) When the company starts to sell assembled kits, a new buyer would already have rich community resources to learn, fix, customize, and innovate the product on his own, as both company and community have already accumulated a good quantity of experience. This may accelerate the transformation of a nondeveloper to a developer, making community behaviors more dynamic over time. 5) When the company grows bigger, a major population in the community is going to be made up of non-developers. They may not choose or be able to contribute to the technology, but they contribute directly to the company's revenue. 6) Apart from development-related contributions, the community can provide contributions to external resources, such as funding resources, manufacturing resources, market information, sales channels and sales promotion, which could be even more important than technological contributions for early stage companies. Because of these differences, we see that previous frameworks have difficulties in explaining community behaviors in profit-seeking open source hardware projects.

The scraped forum posts reflect the community's online behaviors. In general, posts can be divided into two categories - tech-related posts (sold green boxes with color gradient in Figure 2) and non-tech posts (solid purple boxes in Figure 2). The tech-related posts can be further divided into four sub-categories according to the post content's innovativeness. Posts about bugs and issues have the lowest degree of innovativeness. For example, in the OpenROV forum, many posts report a lost of camera signal. In Ultimaker forum, nozzle jamming and calibration issues are frequently seen. Applications of current products include two types of posts. One is about showcasing a new application. In the OpenROV case, one community member was adding a robotic arm to the body of the OpenROV2.8 with a good control of buoyancy so that the underwater drone could grab things. In the Ultimaker case, one community member tested a new filament of a polymer/wood composite with the goal of 3D-printing an object with the feeling of a wooden craft. Another application post shows that one community member wants to develop a new application but is encountering some issues. As a result, he looks for help from the community. A more innovative tech post is about improvement in current products. For instance, one community member was helping the OpenROV team to make a user interface software program, Cockpit, so that users could see the camera video live on their smartphone or computer. In Ultimaker, it was also the community who co-developed the 3D printing software, Cura, converting CAD files to 3D printer readable files. The most innovative posts are from community members sharing personal projects related to breakthroughs associated with the current product. In the OpenROV case, a community member from The University of Toronto shared his design of an ROV (Remotely Operated Vehicle) for iceberg exploration to inspire the firm and other community members.

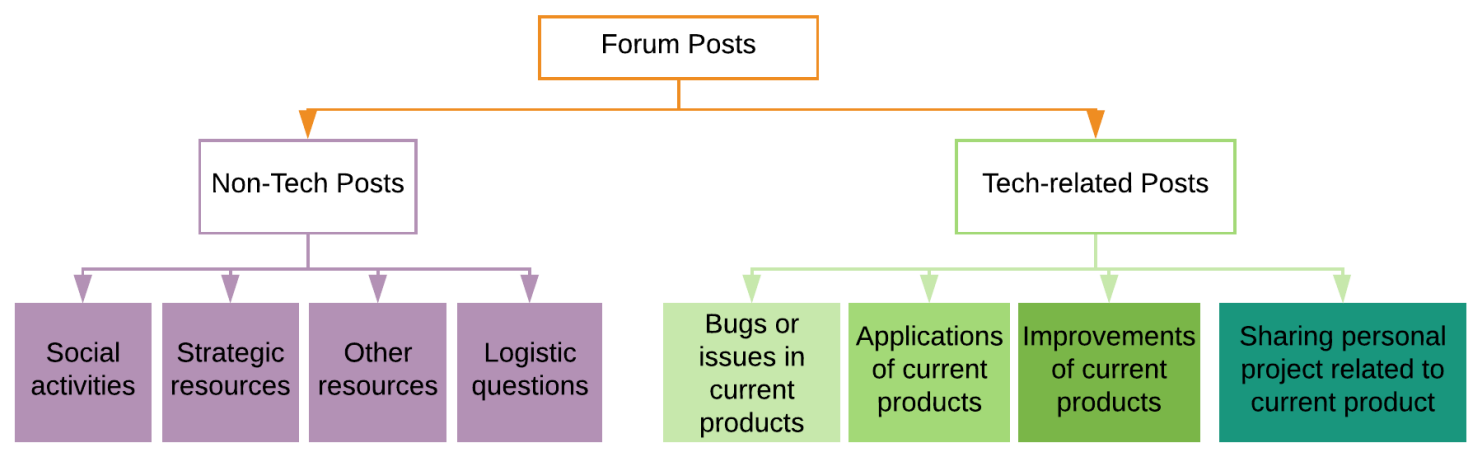

Figure 2. Categories of forum posts

Non-tech posts include socialization activities, such as "Coffee Chats" in the Ultimaker forum and "Meet ups" in the OpenROV forum. Most social activities were not organized by the firm but by community members. Some sub-communities also formed because of language barriers or differences in time zone. Some posts include strategic resources. For example, in the OpenROV case, we have seen a Brazilian community member explaining the Brazilian market and expressing his willingness to assist OpenROV when they open a shop in Brazil. Posts related to logistic resources include suggestions about documentation, packaging and website delivery, etc. Other resources include new policy, new markets and personal expressions of gratitude. 


\subsection{Community's contributions}

From interviewing 37 open source hardware startup founders, we learned that the community can contribute to the firm in four ways (see Table 1) in addition to purchasing the product.

First, communities can help firms by co-developing their products. Community developers include three categories - core developer, feature developer and application developer - according to their technology contributions. This is similar to what Gacek found in the open source software community (Gacek \& Arief 2004). To facilitate understanding, we use the OpenROV case as an example.

In OpenROV, core developers are the community members who helped the firm develop breakthrough technologies such as use of a 100-meter tether (the best current market option is 50 meters) to connect, charge and communicate with the ROV. Entrepreneur interviewees told us that core developers were like the team. Actually, 31 out of 37 entrepreneurs hired their core community developers to work for the company. 17 out of 37 interviewees confirmed that core developers exist in their community. Most core developers joined the firm's community before sales, usually when the firm had just announced its product idea with a prototype (for example through a Kickstarter campaign or at a Maker Fair). Most core developers use their own money and time to help the firm develop the products.

Feature developers were community members who helped the firm to develop the products' additional features and to open source the feature designs into the community so that other members could use them too. Firms may not necessarily adopt the new features in their products. For instance, in the OpenROV case, a community member pointed out that if the body was painted blue, sharks might treat the drone as a fish and bite it. OpenROV adopted this suggestion and changed the body color to white. However, there were other community members sharing how to design a connection to VR glass, but the OpenROV team didn't adopt this option. Rather, OpenROV helped them to develop it. According to the interviewees, feature developers help make the product more usable for diverse utilization scenarios and so increase the firm's addressable market. Feature developers frequently joined the team after sales began.

Application developers are community members who use the product in different applications. In the OpenROV case, there were community members showcasing their usage of OpenROV not merely in underwater photo shooting or treasure hunting, but also in riverbed garbage collecting and water quality surveillance. Application developers joined the community at a later stage when the firm has developed its APIs or SDKs. Application developers may also help firms enlarge the addressable market by illustrating more utilization scenarios and thus inspiring potential clients. Moreover, as they showcase their user experiences, application developers can be of great help in marketing.

Second, the area in which the community can contribute is in product testing and improvement. Before sales, firms always send products to active community members to test the quality. Within our interviews, we haven't observed any companies paying their community to do product testing. After sales, by nature, if issues have occurred, we observed that tech-capable users have attempted to solve the issues on their own and then to report back to the forum about how to fix the issue. There are also community members actively reporting their user experiences and suggestions. These two types of consumers are called active consumers. The active consumers help the firm greatly reduce the cost of testing and technical support. The founder of Lemaker (a microprocessor firm in Shenzhen, http://www.lemaker.org/) said, "without our community's help, I would hire one more electronic engineer for testing and 2 more software engineers for technology support!"

Third, the community can contribute to community facilitation. The community is the soul of an open source firm. A good community culture can trigger recurrent purchasing and increase word of mouth. There are three types of community facilitators - tech facilitators, non-tech facilitators and sharers. Tech facilitators help the community members to answer their questions. They make the community feel that they are being supported at any time. Non-tech facilitators organize community get-togethers or propose non-tech projects, helping community members to bond with each other. Sharers share their related personal projects to add new knowledge and perspectives to the community. Fourth, the community contributes to the firm's managerial activities. Most founders, when they launch their product, are not experienced enough to manage the firm. Their resources for recruiting the right people and for connecting with the right suppliers, manufacturers and distributors are also very limited. According to many entrepreneur interviewees, the community performed an important role in helping the founders to be good leaders and managers. The community's roles can be divided into mentor, resource introducer, information collector and advertiser. Mentors are community members who help firms to identify market needs, design requirements, a business model or financial solutions. 
In the OpenROV case, most community mentors are in private contact with firm leads. From time to time, they communicate with founders through mechanisms like Google Hangout to discuss their opinions and suggestions about the company's growth. The resource introducer introduces financial, distribution, and manufacturing resources, etc. to the company. For example, the OEM resource of OpenROV was introduced by a community member. An information collector shares information about the market, competitors, policies, new technologies and opportunities for the community. An advertiser writes blogs and shares firm information with the broader social media audience. Some advertisers can be really influential in driving a lot of traffic to the firm's website. For example, a highly subscribed tech-review Youtuber one day reported on the OpenROV products in his video and triggered a large number of registrations on the OpenROV's forum.

\section{Table 1. Summary of different contributors' role and their behaviors}

\section{Community Roles}

\section{Development}

- Core developer: shares, co-designss or refine the core structure or components of the open source hardware product. Mostly joins the community in the very beginning

- $\quad$ Feature developer: develops new or refines existing features related to the product. Most are buyers and join the community after sales begin.

- App developer: develops new or refines existing applications. Most join in the community after the products have APIs.

\section{Product Testing Improvement}

- $\quad$ Active consumer: gives feedback about user experience, expresses needs, and proposes new ideas, features or recommendations to the firm.

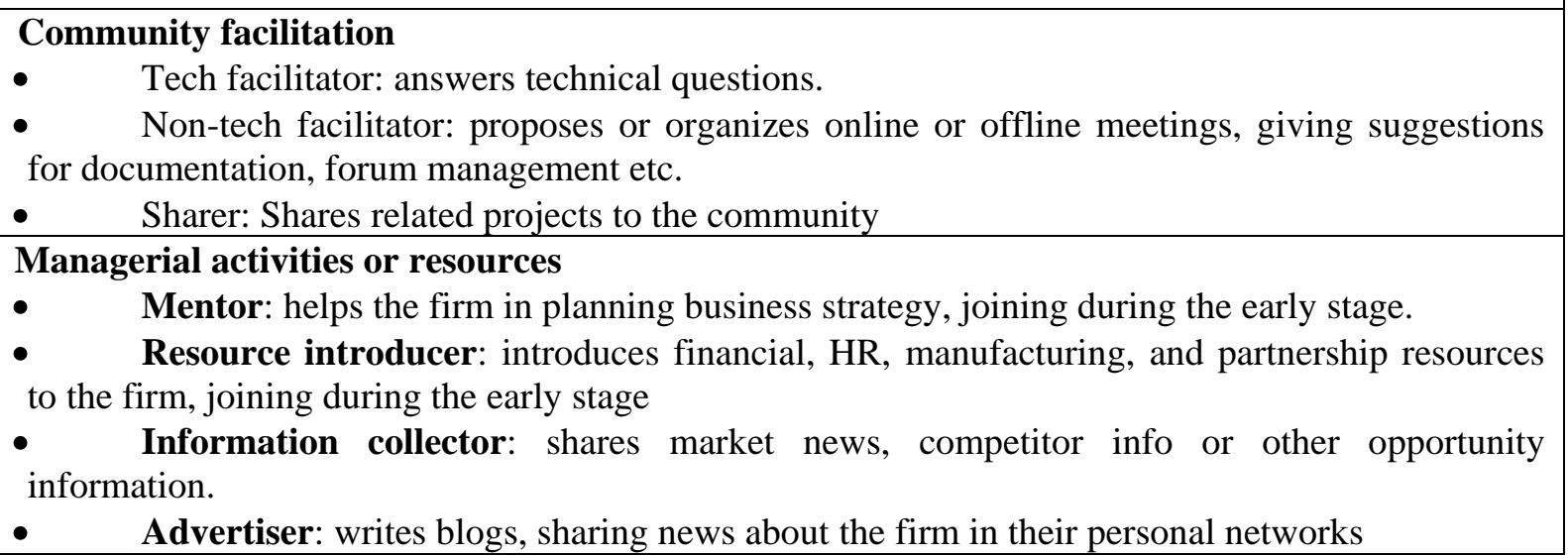

\subsection{Community's response to a profit-seeking purpose}

One might think that the firm beginning to seek profit would drive the community away. Actually, the community interviewees showed significant understanding in this regard. One interviewee told us that "No one will work on it forever without any pay. At least, I hope he (the founder) could get something out of that. Otherwise, he would get a job. "Another interviewee said, "I believe this is the best way (profit-seeking way) to get the project done". Most interviewees didn't care about the economic purpose since they need to pay for materials, either from the firm or from somewhere else, to get the product whether the firm is for-profit or non-profit. However, they mentioned something interesting about how economic purpose may influence their expectation on the quality and progress of the product and the development process. If the firm is or becomes for-profit, the community may pay more attention to the novelty, purpose, and quality of the product and the entrepreneurs' personal charm and the firm's community management methods. When community members join a profitseeking project, they would expect the product to be elegant and of good quality.

Novelty is an important factor to attract core developers. One community interviewee who was a core developer told me that he joined the community since "From the design of the product, I can feel the founder's imagination and artistic charm." Entrepreneur's personal charm can inspire and motivate all community members to contribute. Community members are able to feel the efforts of the firm's 
community management. "I really miss the day when $E$ (the founder) was around (on forum). Now I don't think the community manager understands what people are saying."

One thing to be noticed is that we may have a bias in sampling, as all interviewees are active community members who already made good contributions to product development. They may have more positive attitudes towards the influence of profit-seeking purpose.

This section of the research generated a set of hypotheses that are worthy of further study:

H1: profit-seeking purpose doesn't influence the community's willingness to contribute

H2: The product's elegance positively influences the community's willingness to contribute

H3: The entrepreneurs' engagement with the community positively influences the community's willingness to contribute

H4: The firm's community management positively influences the community's willingness to contribute

\section{CONCLUSIONS AND FUTURE WORK}

In this paper, we are interested in behaviors of the associated community in firm-led open source hardware projects. We used interviews, case studies, and grounded theory to address 1) how the community contributes to the project; and 2) whether being firm-led and profit seeking eliminates the willingness of the community to participate. Through interview and forum data, we formulated a community behaviors and roles framework. Some qualitative evidence has been gathered about influencers of the community's willingness to participate. It is shown that profit-seeking purpose does not necessarily drive the community away.

In future work, we intend to improve our understanding of community behaviors in the following dimensions:

- What influences the community's willingness to contribute?

- How does the community's contribution influence the company's performance?

- How do entrepreneurs make decisions on adopting of the community's contributions?

- How do companies motivate their communities to continue contributing?

\section{ACKNOWLEDGEMENT}

We would like to sincerely express our gratitude to the three anonymous reviewers to give us feedback and suggestions to improve the quality of this work. We would also like to thank all interviewees for their participation, especially for Zack Johnson, Natsuo, Adam Benzion, Cang Hai, Jimmy Lai, Xinghua Liu, Ting Hang Lu, Richard Hulskes and Cong Su.

\section{REFERENCES}

Alexy, O. and Reitzig, M. (2013), "Private-collective innovation, competition, and firms' counterintuitive appropriation strategies”, Research Policy, Vol. 42 No. 4, pp. 895-913.

Bagozzi, R.P. and Dholakia, U.M. (2006), “Open Source Software User Communities: A Study of Participation in Linux User Groups”, Management Science, Vol. 52 No. 7, pp. 1099-1115. Available at: http://pubsonline.informs.org/doi/abs/10.1287/mnsc.1060.0545.

Bonvoisin, J. et al. (2017), "Current state of practices in open source product development". 21st International cnference on engineering design, ICED17, (August), pp. 26-28.

Bruijn, E. De (2010), On the viability of the Open Source Development model for the design of physical objecLessons learned from the RepRap project, University of Tilburg. Available at: http://onlinelibrary.wiley.com/doi/10.1002/cbdv.200490137/abstract\%5Cnhttp://scholar.google.com/schol ar?hl=en\&btnG=Search\&q=intitle:On+the+viability+of+the+Open+Source+Development+model+for+the +design+of+physical+objec\#0.

Dahlander, L. (2007), "Penguin in a new suit: A tale of how de novo entrants emerged to harness free and open source software communities". Industrial and Corporate Change, Vol. 16 No. 5, pp. 913-943.

Dahlander, L. and Magnusson, M. (2008), "How do Firms Make Use of Open Source Communities?”, Long Range Planning, Vol. 41 No. 6, pp. 629-649. Available at: http://dx.doi.org/10.1016/j.lrp.2008.09.003.

Fjeldsted, A. et al (2012), "Open Source Development of Tangible Products”, NordDesign 2012, pp. 1-9.

Gacek, C. and Arief, B. (2004), “The Many Meanings of Open Source”, IEEE Software, Vol. 21 No. 1, pp. 34-40+4. 
Gassmann, O., Enkel, E. and Chesbrough, H. (2010), “The future of open innovation”, $R$ and D Management, Vol. 40 No. 3, pp. 213-221. Available at: http://dx.doi.org/10.1080/08956308.2017.1255054.

Habibi, M.R., Laroche, M. and Richard, M.O. (2014), "The roles of brand community and community engagement in building brand trust on social media", Computers in Human Behavior, Vol. 37, pp. 152161. Available at: http://dx.doi.org/10.1016/j.chb.2014.04.016.

Harhoff, D. and Lakhani, K.R. (2016), "Revolutionizing Innovation: Fundamentals and New Perspectives”,. In Revolutionizing Innovation: Users, Communities and Open Innovation. pp. 1-39.

Hellenes, Ø. (2016), The Impact of Social Capital on Entrepreneurial Activity in Makerspaces, Hackerspaces and Fab labs. Norwegian University of Science and Technology. Available at: https://brage.bibsys.no/xmlui/handle/11250/2433794.

von Hippel, E. (2017), “Free Innovation by Consumers-How Producers Can Benefit: Consumers' free innovations represent a potentially valuable resource for industrial innovators", Research-Technology Management, Vol. 60 No. 1, pp. 39-42.

Hippel, E. Von (2001), "Innovation by User Communities : Learning from Open-Source Software”, MIT Sloan Management Review, pp. 82-86.

Hippel, E. Von (2002), “Open Source Software and the "Private-Collective” Innovation Model : Issues for Organization Science i Open Source Software and the " Private-Collective "Innovation Model : Issues for Organization Science", Organization Science, Vol. 14 No. 2003, pp. 208-223.

Jaspers, A., 2014. Understanding the Motivations of Open-source Hardware Developers: Insights from the Arduino Community. Universidade Católica Portuguesa.

Kyriakou, H. and Nickerson, J. V. (2014), “Collective Innovation in Open Source Hardware”, Ssrn, (Tuomi 2002), pp. 1-4.

Lakhani, K.R. (2016), "Managing Communities and Contests to Innovate with Crowds Crowds”, In Revolutionizing Innovation: Users, Communities and Open Innovation. pp. 1-43.

Lakhani, K.R. and Wolf, R.G. (2005), "Why Hackers Do What They Do : Understanding Motivation and Effort in Free / Open Source Software Projects”, In Perspectives on Free and Open Source Software. pp. 1-27.

Li, Z., Ramos, J.D. and Yang, M. (2017), "Why Open Source? Exploring the Motivations of Using an Open", Proceedings of the ASME 2017 International Design Engineering Technical Conferences and Computers and Information in Engineering Conference IDETC/CIE 2017

Malinen, T. et al. (2011), "Community created open source hardware: A case study of eCars - Now!", First Monday, Vol. 16 No. 5, pp. 1-8.

Martinez, M.G. and Walton, B. (2013), "Crowdsourcing: The potential of online communities as a tool for data analysis". Open Innovation in the Food and Beverage Industry, Vol. 34 no. 4, pp. 332-342. Available at: http://dx.doi.org/10.1016/j.technovation.2014.01.011.

Mellis, D. and Buechley, L. (2012), "Collaboration in open-source hardware”, Proceedings of the ACM 2012 conference on Computer Supported Cooperative Work - CSCW '12, p. 1175. Available at: http://dl.acm.org/citation.cfm?doid=2145204.2145377.

Moritz, M., Redlich, T. and Wulfsberg, J.P. (2016), Value Creation in Open-Source Hardware Communities: Case Study of Open Source Ecology. , pp. 1-6.

Muniz, A. and Thomas, O. (2001), "Brand Community". Journal of consumer research, Vol. 35 No. 1, pp. 46-55.

Prahalad, C.K. and Ramaswamy, V. (2004), "Co-creation experiences: The next practice in value creation", Journal of Interactive Marketing.

Rubow, E. (2008), “Open Source Hardware: Examples of OSH Projects”, International Journal of Solar System Studies, pp. 1-5. Available at: http://www.ncbi.nlm.nih.gov/pubmed/19352529.

Way, N.A. (2002), “Coase's Pengui, or Linux and the NAture of the Firm”, Yale Law Journal, Vol. 112. Available at: http://www.benkler.org/CoasesPenguin.html.

Weber, S. (2004), The success of open source., Harvard University Press, Cambridge, MA, 2004. Available at: http://libproxy.mit.edu/login?url=https://search.ebscohost.com/login.aspx?direct=true\&AuthType=cookie, sso,ip,uid \&db=cat00916a\&AN=mit.001264781\&site=eds-live. 